\title{
MANGA COM LEITE: Teatro na Escola
}

\author{
MANGA COM LECHE: \\ Teatro en la Escuela
}

\section{MANGO WITH MILK: Theater at School}

\begin{abstract}
Maria Lyra
\section{RESUMO}

Neste ensaio compartilho minha experiência como professora de Teatro em uma escola do bairro Morumbi, em Uberlândia, colocando em perspectiva as suas ambiguidades, fragilidades, forças, o encontro com diferentes olhares sobre educação e os atravessamentos afetivos do mesmo. Busco revelar os sabores e as indigestões do encontro, provocando-nos a pensar sobre determinadas crenças que dificultam o diálogo entre diferentes perspectivas sobre aprendizagem.
\end{abstract}

PALAVRAS-CHAVE: artes, diferença, educação.

\section{RESUMEN}

En este ensayo comparto mi experiencia como profesora de teatro en una escuela del barrio Morumbi, en Uberlândia, poniendo en perspectiva sus ambigüedades, fragilidades, fuerzas, el encuentro con diferentes miradas sobre educación y los atravesamientos afectivos del mismo. Busco revelar los sabores y las indigestas de los encuentros, provocándonos a pensar sobre ciertas creencias que dificultan el diálogo entre diferentes perspectivas sobre el aprendizaje.

PALABRAS CLAVE: artes, diferencia, educación.

\begin{abstract}
In this essay I share my experience as a theater teacher at a school, in a neighborhood of Uberlândia named as Morumbi. I try to put on perspective its ambiguities, fragilities, strengths, the encounter with different visions about education and the affective crossings of it. I try to reveal the flavors and the indigencias of the meetings, provoking us to think about certain beliefs which make difficult the dialogue between different perspectives on learning.
\end{abstract}

KEYWORDS: arts, diferences, education.

\footnotetext{
${ }^{1}$ Universidade de São Paulo. Doutorado. Pesquisa em andamento. Pedagogia do Teatro/Formação do artista. Orientador: José Batista Dal Farra Martins. Maria Lyra( Maria Cláudia S. Lopes) é poetisa e professora de teatro, sua área de pesquisa é voz.
} 


\section{Pequena dramaturgia sobre crenças}

As coisas que já existiam em nossa pré-existência são as coisas que já estavam aqui muito antes de nós e provavelmente de um jeito ou de outro continuarão existindo muito depois. São coisas para as quais a gente se prepara e que defendemos por pressuposto e que se perpetuam infinitamente mesmo passíveis de pequenas mudanças são coisas que se movem muito lentamente como pedras e que não parecem se movimentar a olhos nus ou poderia afirmar que só o olho estando muito nu muito despido para que as sutis mudanças das coisas imutáveis sejam notadas. Os pensamentos também são coisas como pedras. Os pensamentos atuam e criam a materialidade das outras coisas que nos envolvem - Deixar o chinelo com a sola virada pra cima faz a mãe da gente morrer. Escola é uma coisa de muito antes. Teatro é uma coisa de muito antes. Que a arte pode transformar é antigo, que a escola serve para educar é pré-histórico, que o professor de artes é diferente dos outros professores porque é mais sensível e mais aberto para ressignificar o espaço, os papéis, a realidade e os outros não sei de quando é mas só sei que levava no bolso desde muito e tinha um peso no fundo. Mesmo junto com aquele outro pensamento mais recente de que não, de que entramos para uma comunidade, de que o professor de artes não é mais sensível nem melhor ou mais descolado ou mais disposto a realmente ouvir. Abrir o guarda-chuva dentro de casa dá azar. Coçar a mão direita é sinal de dinheiro. Deixar o garfo cair é que vem visita. Se não abrir a porta pra visita sair, ela não volta mais. Eu estava muito certa sobre a eficácia de nossa disponibilidade para dialogar, muito confiante de que eu poderia introduzir a linguagem de teatro na escola, acostumada em receber apenas professores de artes visuais. Apostava no quanto poderia fazer com as crianças, nos momentos de fruição, criação, conversa, em aprendizados construídos no prazer e na parceria. Escola é coisa antiga mas não desista não desista. Assoviar dentro de casa atrai cobras. É encantador. É 
impossível. O que é que significa desistência? Quando é que renunciar se torna um ato de amor? Eu dizia para os estudantes de licenciatura, sempre em crise, nas suas afirmações de que o curso não nos prepara para a escola e eu dizia a eles que o curso universitário não tem a função de simplesmente prepara-los para se adaptarem ao que já está estabelecido mas provocar o questionamento e a confiança na transformação e no diálogo. Que devíamos colocar foco no que é possível fazer que como me dizia aquele amigo professor que é nas brechas e nas frestas que é nas fissuras dos duros muros de cimento é que plantamos flor. Joguei muitas sementes, às vezes plena de amor e de alegria e noutras afogada em desespero e solidão, mas não fiquei pra ver o que brotou. Sei o que brotou em mim e que essas palavras são flor. Quero falar sobre desistir. Quero falar sobre desistências. Falar até que ponto a flexibilidade é nosso grande trunfo e o quanto negligenciamos só para continuar e fazer dar certo de que as pedras continuem a ser pedras. Se o galo cantar enquanto se faz careta nossa cara fica deformada pra sempre. Vamos falar sobre deformidades, sobre os panos quentes, sobre o sol coberto por peneiras, a poeira embaixo do tapete que não se vê mas que provoca brotoejas enquanto a vida passa e as crianças crescem sozinhas mas sabendo se enfileirar direitinho e nós envelhecemos cansados doentes e tristes por não conseguirmos exercitar a nossa máxima capacidade humana porque não queremos incomodar aquilo que já existia antes de nós. Tomar leite com manga faz mal. Quantos de nós se sentem intoxicados de giz, de amor não dado, de ideias não realizadas, de maus entendidos, de sapos engolidos? Ser educado é fingir que somos aquilo que esperam que a gente seja mesmo que esse aquilo seja infinitamente menos interessante do que poderíamos ser? Somos como aqueles cachorros magros e negligenciados do Morumbi, não morremos de fome graças a bondade das cantineiras mas vivemos como quem se arrasta com medo das mudanças reais que poderiam vir, presos aos sistemas feitos para nos 
ajudar a não viver nem morrer mas a continuar. Comer semente de melancia faz nascer um pé de melancia dentro da barriga, não coma na frente do espelho, não coma manga na frente do espelho, não coma manga com leite nem pule no rio pois você pode morrer quando o medo da morte faz com que nos arrastemos sem esperança de sala em sala após cada sinal quando os protocolos feitos para ajudar a escola tornam-se empecilho para que qualquer aprendizado realmente aconteça.- Tia, eu te amo tia você é a melhor professora a professora mais legal tia eles fazem o que querem na aula da senhora tia é sempre assim quando eu gosto de alguém a pessoa vai embora tia deixa eu ir no banheiro tia deixa eu beber água tia leva a gente pra fora tia leva a gente pra fora tia me deixa desenhar tia você é sapatão? Tia que saudade da senhora não falta deixa eu levar seu caderno eu estou chorando porque você não me deixou ir pegar o livro de ocorrências de novo tia eu adoro você toma essa flor. Joguei muitas sementes às vezes plena de amor e de alegria e noutras afogada em desespero e solidão, mas não fiquei pra ver o que brotou. Sei o que brotou em mim e que essas palavras são flor.

Da chegada na escola e do transbordamento de afetos.

A Escola Municipal Hilda Leão Carneiro, situada no Bairro Morumbi, em Uberlândia, conta com os três turnos como períodos de ensino. Em Outubro de 2016, eu havia desenvolvido na escola a contrapartida social de um projeto literário (Inventos- quando venta do lado de dentro) aprovado pela lei municipal de incentivo e que me deixou na memória o encantamento do encontro e a curiosidade saborosa das crianças. Deste modo, quando tive que escolher uma escola para dar aulas de "artes" na prefeitura, escolhi de uma lista de muitas a Escola Hilda Leão Carneiro. Havia gostado muito da experiência do projeto, ser visitante na escola é muito diferente do que estar lá, todos os dias. Como visitante, não sentimos a pressão da rotina, nem dos regulamentos da escola. Somos novidade que provoca interesse e depois se vai. Os 
desafios de voltar todos os dias, de conhecer de fato as crianças e de se relacionar com todas as contradições da escola são muito diferentes.

Após cumprir a burocracia do contrato, que incluiu tomar algumas vacinas, passar pelo exame médico, assinar os papéis e dar entrada na escola, comecei! De certo modo me senti muito agradecida e entusiasmada por voltar a trabalhar com crianças, voltar a ser professora de teatro para outras idades. Cheguei de peito aberto, respirando fundo. - Você é a professora nova de artes, não é? Eu sabia - Afirmou uma das professoras efetivas, me olhando de cima embaixo. - Sempre quando tem esse estilo diferente assim é porque é de artes.

Prédio grande, longas rampas e corredores, pátio interno, quadra, quiosque, um espaço gramado imenso, biblioteca, sala de multimeios, e até um teatro de arena pequeno e coberto! No minuto que conheci o espaço de arena tive certeza de onde seriam as nossas aulas. Muitas possibilidades surgiram.

Fiquei com uma turma de $3^{\circ}$ ano, quatro turmas de $4^{\circ}$ ano e cinco turmas de $6^{\circ}$ ano. Me agradava muito o encontro, sobretudo com os menores. Na chegada da escola, o que mais me chamou a atenção foi o transbordamento de afetos: rodeada por crianças que vinham me receber na porta, que abraçavam apertado, que declaravam o amor através de bilhetes, desenhos, balas velhas e flores roubadas. Como foi acolhedor estar envolta por aquelas mãos pequeninas, como me mobilizei com as dezenas de anedotas brotando das bocas e olhos tão acesos durante os encontros, como me inquietavam os desafios em relação às perguntas, ao tempo, ao espaço e mesmo aos conflitos que pouco a pouco surgiam em relação à direção da escola. 


\section{Das indigestões}

A aula da festa!

Um dos recorrentes desafios para o professor de teatro que chega na escola ainda é espacial. - Se a sala está cheia de carteiras, arrastemos. Vamos abrir espaços! Vamos usar as carteiras para construirmos outros espaços, instalações, relações de corpo-arquitetura.

Inspirada pela leitura de Carmela Soares (2003), em que ela aproveita os espaços da escola e o que se apresenta para exercitar e desabrochar o olhar estético das crianças, não me dei conta de que este "desafio espacial" vai muito além do que a nossa possível preguiça na modificação do espaço ou mesmo no diálogo com ele. Este desconforto vai além de o teatro não ser realmente aceito, por muitas escolas, preferencialmente como linguagem artística a ser trabalhada em si. Ele ultrapassa a questão também incômoda do tempo viável para transformar a sala, arrastando as carteiras do lugar e depois voltando. O "bancarismo" é um ranço, um pensamento sobre a educação ainda muito predominante.

Educação é preparação, educação é disciplina, educação é fazer atividades, é cumprir tarefas, é copiar, copiar, copiar, mesmo não tendo sido ainda alfabetizado. É fazer muitas coisas às quais não se confere sentido já que muitas crianças de $6^{\circ}$ ano, embora soubessem copiar, não sabiam ler o que estavam copiando. Muitos educadores na escola se preocupavam com as crianças não alfabetizadas, havia professores trabalhando duramente para mudar isso, em meio a esta "batalha em defesa da educação" as aulas do teatro pareciam ser um desserviço.

Trabalhamos com formas teatrais ou com a ideia de esculturas vivas. Exploramos planos diversos do espaço, que incluíam as mesas. Em um dos encontros nós chegamos a nos sentar sobre as carteiras, brincamos de ressignificar a cadeira como objeto, afastamos as carteiras pra frente, pra trás, e, muitas vezes, deixamos elas no lugar para testar o que poderíamos fazer com elas, ou porque em alguma aula ou outra minha energia faltava para fazer mudanças na configuração do espaço. Essa disposição foi falhando cada vez mais e o espaço só refletia o quanto eu estava perdendo na "batalha pela educação". 
A criança é performer e polimórfica, trabalhemos com o que elas possuem de presença e não de falta (MACHADO,2010) e a escola está repleta de vida que pulsa nas e das crianças, seu desejo de descoberta e de experiência. Nas aulas eu tentava estabelecer um espaço pra cantar e explorarmos sonoridades, para ouvir os desejos possíveis. Numa mistura de entusiasmo descontrolado, energia física represada e não costume com outras formas de aprender, o tal "controle" era coisa muito relativa, mas de início eu ainda preferia o caos vivo que lidar com os corpos passivos imersos no tédio e na obediência. Vez ou outra a porta se abria para que a merendeira contasse os alunos presentes. Vez ou outra eu percebia o impacto do que parecia uma grande bagunça e me envergonhava. Me envergonhava mesmo sabendo que, trabalhando teatro, a polifonia de movimentos e sonoridades fosse esperada.

- A aula da festa! Indagou a senhora que vigiava os corredores e rampas e que naquele dia abriu a porta para contar os estudantes. O seu tom era de desaprovação e justo em um dos momentos em que eu avaliava o encontro como produtivo. Pensei muito sobre a ideia de festa a partir deste comentário. Pensei que as nossas escolas poderiam ser mais festivas, que nossos aprendizados nela fossem mais prazerosos para todos. Ali, implicitamente, a senhora que vigiava os corredores revelava mais uma vez certa perspectiva em relação ao que significa aprender. Fica claro que a vida da festa e do encontro é imediatamente julgado como não-educação, como bagunça aleatória- e até ela tem o seu papel. A batalha pela educação que a escola travava me parecia desconsiderar a realidade dos corpos explosivos, pelo desejo de criar e brincar para instaurar um movimento contínuo de ordem, de silêncio, de fazeres sem sentido real para a criança.

Pela falta de tempo e espaço para festa, assim que surgisse qualquer proposta com a mínima margem de liberdade, as crianças também a destruíam pela excessiva avidez, por fome, devoravam de qualquer jeito e muito rápido sem saborear o momento, sem ouvir as poucas regras dos jogos, se perdiam nos labirintos da falsa liberdade, e por que não fazer dar as mãos entre a festa e as regras? - Professora, as crianças estão ficando muito agitadas na sua aula...você poderia trabalhar uma atividade mais relaxante, ao final, para que o próximo professor consiga trabalhar? 
Eu compreendi o pedido, mas não deixei de me questionar sobre como seria pedir que a supervisora solicitasse aos outros professores para que movessem as crianças, para que elas não estivessem com o "bumbum" tão quadrado quando eu chegasse. - Professora, o barulho está atrapalhando os outros professores e salas, está atrapalhando o barulho, professora, vim ver o que está acontecendo o barulho de arrastar as carteiras, as crianças em movimento. Numa tarde, três vezes me pediram silêncio e eu pedia às crianças para termos cuidados, para não atrapalharmos as outras aulas, mas mesmo assim nós atrapalhávamos. Ao entrar na sala de professores, no recreio, alguns me torciam o nariz, eu pedia as crianças, por favor, vamos fazer menos barulho e qualquer barulho atrapalhava.

O incômodo em relação ao espaço não apropriado é muito pequeno em relação ao incômodo gerado pelos atravessamentos de trabalhar teatro como linguagem. Talvez porque ele esteja mais perto das transgressões do que das ações "educativas". Professora, eu queria te pedir que com o $3^{\circ}$ ano você pare mesmo de trabalhar com teatro e faça atividades de coordenação motora. Professora, sete desses meninos são do atendimento educacional especializado, é uma turma com muitas dificuldades. Professora, queria mesmo que você parasse de dar a sua aula e ajudasse a professora regente, eu te passo atividades de recortar e colar. É pra você parar mesmo, jogar fora as suas ferramentas e possibilidades com o teatro e fazer com eles o que eles já fazem em todos os outros horários. Mesmo tendo começado um outro projeto, desista dele e faça o que eu estou te pedindo, o que você quer fazer não tem valor, não tem o mesmo valor. Afinal, alfabetizar é só saber ler ou talvez só saber copiar pra continuar calmo e silencioso, para preparar esses alunos para que consigam ser mão de obra barata, assim já está bom.

As indigestões são oportunidades que quando olhadas apontam caminhos a serem explorados, tensões a serem reconhecidas, diálogos a serem construídos quando a hierarquia não se torna impedimento. Professores não devem ser apenas executores de planos alheios, operários de uma fábrica cujo produto final da linha de produção é desconhecido, num sistema feito para falhar. Algumas escolas tem planos muito rígidos e mesmo que a nossa abordagem vá sendo criada junto a planos maiores (da escola, do sistema educacional brasileiro etc.) é necessário abertura por parte da 
instituição - Para isso é preciso apenas disposição para dialogar, para que a escola possa, de fato, compreender o trabalho com teatro - mas o diálogo não depende só de nós.

De mãos para trás

O quanto estive disposta a ouvir? Me fiz esta pergunta muitas vezes. Me pergunto sobre o quanto a construção do diálogo se faz no desacordo, quando respeitamos a nossa voz e não apenas a voz do outro. Dialogar não é concordar e fazer o que o outro espera, dialogar é também sustentar as nossas ações de acordo com o que sentimos e pensamos, às vezes em oposição ao outro, e a escola é rede feita de muitas tensões. Não pretendo com este texto demonizar a escola e as pessoas que a dirigem, nem essa nem muito menos outras. Sei que por trás do rótulo de pessoas controladoras e de uma "educação alienante" estão também sujeitos amorosos, engajados com a comunidade, que agem a partir da percepção daquilo que as crianças precisam. Pessoas que se importam e que se interessam e que dedicam suas vidas ao projeto de educar.

- Em fila, a fila é formada antes do segundo sinal bater. Em ordem de tamanho, meninas na frente e meninos depois e mãos para trás. Vamos crianças, vamos fazer a fila! Nas primeiras semanas explorava a velocidade, as pausas, pequenos movimentos com braços e formas de se deslocar diferentes ao longo de nosso trajeto que ia da sala de aula até o pátio, descendo a rampa e atravessando os corredores. As crianças ficavam eufóricas e queriam retomar a brincadeira a cada vez que fazíamos a fila. Em parte fui compreendendo que a fila e as mãos atadas "evitam problemas": evitam tapas e socos, evitam quedas, evitam barulho - é uma maneira prática, embora pouco criativa, de se fazer o mesmo trajeto todos os dias, da mesma forma.

Em horário de módulo com a supervisora, a fila e as mãos para trás foram assunto de debate. Me senti um pouco como as crianças que, ao soltarem seus braços, são repreendidas pela senhora que vigia o corredor - Olha a fila, mãos para trás! - É para o bem delas...é para o bom funcionamento da escola. - Mas tia, hoje a gente pode 
imitar as borboletas que nem aquele dia.... - Não podemos...hoje não. - Mãos pra trás crianças...mãos pra trás.... eu também coloco as minhas, assim, para trás.

O quão fácil é moldar comportamentos sem trabalhar sobre a consciência, me pergunto. Como seria fazer um trabalho profundo com as crianças, trabalho de consciência coletiva, para não atrapalhar os outros, de respeito consigo e com o outro, para evitar os tapas. Como seria criar esses espaços reais em que as emoções fossem trabalhadas e não medicadas, onde as escolhas fizessem sentido para todos e não fossem simples ordens a serem cumpridas para o que julgam ser um bom funcionamento. Muitas escolhas eram feitas para evitar problemas, para não ter que lidar com as questões reais que se colocavam.

O que os pais vão pensar?

Quem se lembra do espaço de teatro de arena? O sonhado espaço que, ao conhecer, tive certeza de que seria meu espaço de trabalho com as crianças. Nós ocupamos esse espaço algumas vezes. O tempo de chegada e de partida engolia muito dos 50 minutos possíveis de encontro, e eu deixei de ter a ferramenta de aproveitar o trajeto porque "precisam andar com as mãos para trás". Ao chegar lá, com o tempo, tive que aceitar que meus planejamentos fossem muito mais despretensiosos e que acolhessem a necessidade das crianças de simplesmente explorar os espaços e brincar.

- Quando for usar o espaço do teatro de arena, que fica exposto à rua e aos pais, tome muito cuidado ao chamar a atenção das crianças ou tome cuidado com as atividades, pois as mães desse bairro são terríveis. Você não as conhece, elas são terríveis. Seria preferível que caso vocês trabalhem conteúdo fora da sala de aula, que fosse na quadra ou quiosque, desde que não atrapalhe a educação física, porque ali vocês estão muito expostos...

- Tia, deixa a gente ser livre. Gritou G. enquanto eu explicava as regras do jogo "o dono da rua". - Vocês são livres. Gritaram todos e correram eufóricos. Neste dia, três crianças se machucaram sendo livres. Uma delas derrubou a moldura do gol de uma das quadras (gramada) encima da própria cabeça. Outra subiu na árvore alta e ficou presa entre dois galhos, com medo de descer, outra caiu e se arranhou. Não achei 
que a solução fosse parar de sair com elas, para evitar os problemas.... Estava nítida a necessidade de se mover, de gastar a energia represada mesmo durante o recreio - em que eram igualmente vigiadas para não correr - os quinze minutos de recreio. $\mathrm{O}$ excessivo entusiasmo se contrapunha ao tédio e desinteresse dos corpos sentados em sala de aula. Mas com cinco horários seguidos, confesso, não era escolha fácil lidar com essa energia explosiva, tentando dar contorno a ela, pra que as crianças estivessem seguras e a escola não reclamasse.

Como dito, muitas escolhas são feitas para se evitar problemas. Eu também escolhi evitar problemas e deixamos de ir ao teatro de arena, e deixamos de sair tanto assim da sala de aula. Mas os problemas surgem também dentro da sala de aula, os problemas que devem ser evitados.

"Vamos se adaptar à escola"

- Tia, você tem filho? - Não, ainda não. - Então, você tem marido? - Não. Namorado? - Eu tenho uma companheira (pausa e susto). - Tia, você é sapatão????? Tia, eu não tenho preconceito, o que que tem? - Credo, tia, deus não gosta. - Tia, o que importa é o amor, deixa ela gente, o que que tem? (burburinho).

Infelizmente, ainda no século XXI, falar abertamente sobre a diversidade sexual é um grande tabu. Responder com honestidade sobre sexualidade para crianças é manga com leite para alguns. Não previa a repercussão da minha escolha de responder honestamente a elas. No outro dia, durante o módulo, a supervisora me questionou sobre estar ou não trabalhando um tema diferente com as crianças. Em segundos, soube do que se tratava. Contei como foi. Ela disse que entrou na sala logo depois que saí, e que as crianças pareciam agitadas falando que a professora era gay. - Está muito cedo para trabalhar este tema, nunca ouvi falar que a gente tem que trabalhar esse tema com crianças dessa idade!

Expliquei a ela que eu não estava "trabalhando" o tema da homossexualidade. Mas que eu sabia, como criança que se tornou gay, que as crianças deveriam saber desde cedo que é uma opção e que não há nada para se envergonhar. - Sei que as 
crianças que talvez possam vir a ser gays sentem-se muito sozinhas com o que já percebem de si, e elas precisam também conhecer pessoas gays, saber que existem e que podem ser admiráveis, e que não se trata de forma alguma de incentivá-las a definir sua sexualidade, mas a aceitar que na realidade existe desde muito cedo uma diversidade que é ignorada, pela escola, pela "família" etc.

- Muito interessante, mas por que você não responde que é solteira? É mais fácil. Porque os pais também não tem maturidade para lidar com as consequências dessa conversa, eles podem achar ruim, podem reclamar. Respondi à supervisora, com a mesma honestidade que respondi às crianças, que se os pais viessem "reclamar" que seria uma oportunidade de trabalhar com a homofobia na comunidade, que a escola também poderia ter esse papel na educação dos pais. Ela concordou e disse que eu tinha pensamentos muito bons, mas logo que levantei e antes de abrir a porta, pediu: Mas vamos nos adaptar mais à escola, né? Não precisa falar nada, diga que isso não tem importância, que é sua matéria que tem importância, que não importa sua vida pessoal, pra gente não importa. - Vamos nos adaptar mais à escola...

Potências e caminhos a serem trabalhados

- Vocês sabem onde dizem que nasceu o teatro? - Nos Estados Unidos. - Na rua, porque lá tinha espaço. - O teatro nasceu dentro do homem, professora.

Entre tensões inevitáveis no encontro com a diferença, muitos instantes potentes, de alegria, de descoberta, de aprendizagem. Tanto quanto ao receber os abraços espontâneos, esquentava o coração ver um fragmento da aula anterior ressurgir em forma de ação, de comentário, de registro - como quando fizemos o jogo de ressignificar o objeto lenço, ou quando trabalhamos com a ideia de fotografar espaços com uma máquina imaginária. Avistava reverberações, ao ouvir as crianças cantando uma canção aprendida durante a caminhada da fila, ou no pátio. Avistava possíveis percursos para nós, mas precisei abrir mão muitas vezes desses percursos imaginados por mim, porque precisava escutar os desejos das crianças e precisava tentar aproveitá-los da melhor forma, como fosse possível. 
Os próprios conflitos e tensões que emergiram poderiam ser pistas de como e o que mais precisávamos trabalhar: o desejo das crianças de explorar outros espaços, a dificuldade delas de seguir qualquer regra mesmo brincando, o modo desta escola de se relacionar com as limitações dos pais e a constante busca por evitar os problemas, a questão da diversidade sexual, o cuidado com o outro e o auto-cuidado como forma de prevenir acidentes. Toda indigestão real sinaliza que algo que ingerimos não vai bem, um caminho seria lidar realmente com o que não vai bem, com o que machuca e intoxica ao em vez de elucubrar sobre as possíveis indigestões que teremos se misturarmos manga e leite.

\section{$\operatorname{Desistência(s)}$}

Desistir: verbo transitivo indireto e intransitivo: não prosseguir em um intento, abrir mão voluntariamente de (algo); abster-se, abdicar, renunciar a algo ou a alguém. Respirei muitas vezes antes de tomar a decisão de sair da Escola Municipal Hilda Leão Carneiro, no bairro Morumbi. Pensava nas crianças, no que elas sentiriam com a minha escolha. Queria ter certeza de que, se feita, a escolha estaria vindo não do medo, não do cansaço ou da covardia...mas que fosse feita por amor. Ir embora seria como abortar a minha fé de que é possível, de que vale a pena, como em muitas outras experiências positivas que tive, mesmo em escolas. Ficar significava um abandono pior do que julgo como a melhor versão de mim e do trabalho que pode ser feito com teatro nas escolas. Pensei sobre aquilo do qual precisamos nos separar para unir nossos pedaços. Ponderei sobre o significado de desistir e me dei conta de que ficar ou ir seriam apenas desistências distintas - desistir de continuar e encontrar soluções para essas tensões ou desistir do tipo de trabalho em que acredito, de minha perspectiva sobre o que seja educação.

Optei por sair mesmo ainda me questionando sobre a decisão. Vez ou outra as mãos pequenas, os bilhetes, as flores, as anedotas, as perguntas brotam no meio da tarde, sem pedir licença. Pode ser que tenha sido um amor interrompido, um término precipitado, será que ele ia parar de me bater? Minha escolha foi consequência, quero acreditar que inevitável, de uma indigestão real sem precedentes. 
Assumir o fracasso é difícil, ter ensinado aos meus alunos de graduação o quanto é possível fazer um trabalho maravilhoso na escola, e, logo depois, na prática, desistir de uma escola, foi doloroso. Passei a me lembrar de algumas crises que eles traziam e que eu julgava infantis, e mesmo a mania de demonizar a escola e protestar sobre ela como instituição alienante.

Eu não pretendo afirmar que as escolas sejam lugares ruins, muito menos que todas elas sejam horrorosas máquinas de moldar mentes alienadas e passivas, mas, posso falar desta minha recente experiência de fracasso e da minha dificuldade de lidar com a diferença, e da dificuldade da escola de acolher a diferença: minha, das crianças, dos pais, dos outros professores quem sabe...Para que eu pudesse, para que eu fosse capaz de continuar, parada ali diante de uma bifurcação imaginária, a continuidade do caminho teria que ser outro, para que eu suportasse, para que eu não adoecesse, para que eu não me arrastasse de sala em sala desacreditando nos encontros, para que eu não jogasse a minha frustração sobre as crianças, para que eu continuasse querendo ser professora de teatro... Desisti.

\section{Manga com leite}

Passar por baixo da escada dá azar. Cruzar um gato preto é sinal de morte. Grávida de barriga redonda é que vai ter menino. Listra branca na unha aparece quando vai chegar presente. As coisas que já existiam em nossa pré-existência são as coisas que já estavam aqui muito antes de nós. Escola é uma coisa de muito antes. Teatro é uma coisa de muito antes. Assoviar dentro de casa atrai cobras. É encantador. É impossível. O que é que significa desistência? Quando é que renunciar se torna um ato de amor? Que é nas brechas e nas frestas que é nas fissuras dos duros muros de cimento é que plantamos flor. Joguei muitas sementes às vezes plena de amor e de alegria e noutras afogada em desespero e solidão. Eu não fiquei pra ver o que brotou. Sei do que brotou em mim e essas palavras são flor. 


\section{REFERÊNCIAS}

ANDRÉ, Carminda Mendes. O Teatro Pós-Dramático na Escola. Inventando espaços: estudos

sobre as condições do ensino do teatro em sala de aula. São Paulo: Ed. UNESP, 2011.

CABRAL, Beatriz. Pedagogia do Teatro e Teatro como Pedagogia. Anais da IV Reunião Científica de Pesquisa e Pós-Graduação em Artes Cênicas, 2006.

DESGRANGES, Flávio. Pedagogia do Teatro: provocação e dialogismo. SP: Hucitec, 2006.

FREIRE, Paulo. Pedagogia da Autonomia: saberes necessários à prática educativa. Rio de janeiro: editora paz e terra, 2000.

MACHADO, Marina Marcondes. A criança é performer. In: Revista Educação \& Realidade 35(2): 243, 2010, p.115-138.

PUPO, Maria Lúcia S.B. Além das Dicotomias. Anais do Seminário Nacional de Arte e Educação: $15^{\text {a }}$ edição. Montenegro/RS: 2000.

SOARES, Carmela Correa. Pedagogia do Jogo Teatral - uma poética do efêmero. SP: Hucitec, 2010.

Recebido em agosto de 2018. Aprovado em outubro de 2018. Publicado em dezembro de 2018. 